SHORT REPORT

\title{
Occupational asthma due to lgE mediated allergy to the flower Molucella laevis (Bells of Ireland)
}

\author{
W M A J Miesen, S van der Heide, H A M Kerstjens, A E J Dubois, J G R de Monchy
}

Occup Environ Med 2003;60:701-703

Background: About 25\% of greenhouse flower and/or ornamental plant growers sensitised to workplace flowers or moulds have occupational asthma, a disease that is suffered by $8 \%$ of the growers who cultivate these crops.

Aim: To document a case of occupational asthma due to lgE mediated allergy to the flower Molucella laevis.

Methods and Results: There was a history of work related seasonal asthmatic and rhinoconjunctivitis symptoms in a Molucella laevis grower. Bronchial obstruction following exposure to Molucella laevis was documented by a fall in $\mathrm{FEV}$, from $89 \%$ to $73 \%$ of predicted during seasonal exposure to Molucella laevis. Daily PEF measurements showed a fall from 500 to $250 \mathrm{l} / \mathrm{min}$ during this period following withdrawal of inhaled steroids. Bronchial reactivity to inhaled methacholine was increased $\left(\mathrm{PC}_{20}\right.$ $1.45 \mathrm{mg} / \mathrm{ml}$ ). Confirmation of sensitisation to Molucella laevis flower pollen extract was done using an SPT and by demonstration of Molucella laevis specific serum lgE (18 $\mathrm{IU} / \mathrm{ml}$; class 4). Specific inhalation challenge with Molucella laevis extract provoked an early and late asthmatic reaction (EAR and LAR) with a fall in FEV , compared with control day of $40 \%$ and $53 \%$ respectively, with associated 5.1-fold increase in absolute sputum eosinophil cell counts and 2.9-fold increase in neutrophil cell counts.

W orkplace exposure to specific inhaled allergens is an important cause of new-onset asthma and exacerbation of pre-existing asthma. The term occupational asthma (OA) usually refers to new-onset asthma caused by workplace exposure; $5-15 \%$ of new-onset asthma is reported to be occupational in origin. ${ }^{1}$

About 25\% of greenhouse flower and/or ornamental plant growers sensitised to workplace flowers or moulds have OA; $8 \%$ of greenhouse flower growers have OA. ${ }^{2}$

We describe the first case of OA due to IgE mediated allergy to the decorative flower Molucella laevis (fig 1).

\section{METHODS}

The patient was a 60 year old male Molucella laevis grower presenting with progressive seasonal respiratory symptoms, consisting of productive coughing, wheezing, and chest tightness, occurring primarily daily during two hours of work with Molucella laevis in his greenhouse in the early morning and evening, and eventually persisting at night.

Symptoms were confined to the period of pollination of Molucella laevis (June until October) and started in the first year that he was growing this flower. He had experienced two symptomatic growth seasons on presentation to our outpatient clinic.

The greenhouse contained 14000 flourishing Molucella laevis plants in an area of $250 \mathrm{~m}^{2}$ ( $10 \%$ of the total greenhouse). The greenhouse has a yearly production and sale of 90300 stalks

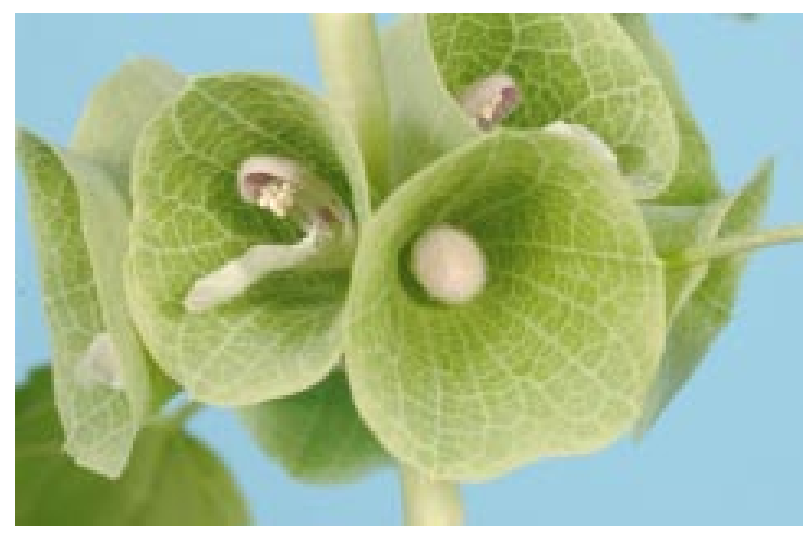

Figure 1 Molucella laevis (Bells of Ireland) is a lightly scented plant that grows 36 inches tall. The 2 -inch, white-veined green bells that cling closely to stems are not really flowers but enlarged calyxes. The true flowers, tiny, fragrant, and white, are deep within the bells. The popular name alluding to Ireland has been applied to this plant only because of the green colour of the bells; it is native to the eastern Mediterranean region, primarily Syria.

per year, representing one third of the production marketed in Aalsmeer (one of five flower whole sale auction centres in the Netherlands). It is estimated that 100 greenhouses grow Molucella laevis throughout the Netherlands. The patient was personally involved in planting, harvesting, trimming, and transporting the Molucella laevis plants.

A protector, colloquially referred to as "dust mask" or "gas mask" was used by the patient. ${ }^{3}$ An air supplying positive pressure, self contained breathing apparatus was used after onset of symptoms and seemed effective in preventing them. However, in the warm climate of the greenhouse (temperature $38^{\circ} \mathrm{C}$ ), perspiration and condensation of the goggle was not tolerated, and caused malfunctioning of the protector. The patient therefore decided not to use it, despite symptoms.

Symptoms decreased after one day of avoiding the greenhouse. Salbutamol inhalation therapy gave immediate relief of symptoms. Rhinoconjunctivitis was associated with the above mentioned respiratory symptoms. His wife (the only other exposed worker in the patient's greenhouse) and one neighbouring colleague who both grew Molucella laevis had no allergic or irritant symptoms while working in the greenhouse. The patient had no prior history of symptoms of allergic diseases. Physical examination revealed expiratory wheezing. Chest radiography and routine laboratory investigations showed no abnormalities.

Abbreviations: $E A R$, early asthmatic response; $F E V_{1}$, forced expiratory volume in 1 second; HEP, histamine equivalent prick test; LAR, late asthmatic response; OA, occupational asthma; PEF, peak expiratory flow; SPT, skin prick test 
Skin prick tests (SPTs) were performed with common inhalant allergens including grass, trees, weeds, house dust mites, animal danders, fungi, food, and latex (ALK, Denmark), as well as with extracts of Molucella laevis flowers (including pollen), and extracts of branches and leaves. Final protein extract concentrations of $0.1 \mathrm{mg} / \mathrm{ml}, 1 \mathrm{mg} / \mathrm{ml}$, and 10 $\mathrm{mg} / \mathrm{ml}$ were prepared in our laboratory.

Preparation of allergenic extracts from Molucella laevis plants was as follows. Flowers (including pollen) were suspended in a $0.01 \mathrm{M} \mathrm{NH}_{4} \mathrm{HCO}_{3}$ buffer ( $\mathrm{pH}$ 7.8) and homogenised in a Vortex blender for 10 minutes in an ice bath. After centrifugation, the supernatant was successively dialysed, filtered, and freeze dried.

Allergens in freeze dried Molucella laevis extracts were biotinylated and immobilised to streptavidin coated Caps of the Unicap system (Pharmacia, Sweden).

Specific IgE binding to the different immobilised extracts and common inhalant allergens including grass, trees, weeds, house dust mites, animal danders, fungi, food, and latex were measured (Pharmacia).

Spirometry was performed for measurement of FEV, (forced expiratory volume in 1 second) with an electronic pneumotachograph (Jaeger, Germany).

Serial measurements of peak expiratory flow (PEF) were recorded by using a Mini-Wright peak flow meter.

The $\mathrm{PC}_{20}$ to metacholine (provocative concentration of metacholine producing a $20 \%$ fall in $\mathrm{FEV}_{1}$ ) was measured according to the method described by Cockcroft and colleagues. ${ }^{4}$

Specific inhalation challenge with Molucella laevis pollen extract was performed using a DeVilbiss nebuliser, as described previously. ${ }^{5}$

Inhaled corticosteroids and $\beta$ adrenergic drugs were discontinued, four weeks and one week, respectively before the Molucella laevis inhalation challenge. Work exposure to Molucella laevis was stopped one week before a four day admission in our hospital for Molucella laevis inhalation challenge testing.

Metacholine challenge followed by sputum induction and processing ${ }^{6}$ was performed two days before (one day before control day) and one day after the specific inhalation challenge.

\section{RESULTS}

SPT with Molucella laevis pollen extract was positive at a concentration of approximately $10 \mathrm{mg} / \mathrm{ml}$ (histamine equivalent prick test $(\mathrm{HEP})=1.0 \mathrm{SPT}$, with the same extract being negative in patient his exposed wife and five healthy non-exposed controls). No other tests were performed with either his wife or controls.

SPTs with the other abovementioned allergens yielded negative results (HEP 0.0). IgE specific for the flower (pollen) extract of Molucella laevis was $18 \mathrm{IU} / \mathrm{ml}$ (class 4). The IgE test for Molucella laevis branches and the common inhalant allergens were negative $(<0.35 \mathrm{IU} / \mathrm{ml})$. Total IgE content was $122 \mathrm{IU} / \mathrm{ml}$.

Sequential spirometry during the Molucella laevis season revealed a declining $\mathrm{FEV}_{1}$ from 3.3 (89\% predicted) to 2.7 litres ( $73 \%$ predicted).

Visual inspection of a serial daily peak flow plot showed a decrease in morning peak flow values from 500 to $250 \mathrm{l} / \mathrm{min}$ within a week after cessation of therapy with inhaled steroids during continued exposure to Molucella laevis. Morning peak flow values returned to $500 \mathrm{l} / \mathrm{min}$ after one week of completely avoiding exposure to Molucella laevis in the greenhouse.

Bronchial inhalation challenge with Molucella laevis pollen with the final pollen extract concentration of $10 \mathrm{mg} / \mathrm{ml}$ induced a dual asthmatic response (early and late asthmatic response (EAR and LAR): a fall in $\mathrm{FEV}_{1}$ of $40 \%$ and $53 \% \mathrm{com}-$ pared with control day, respectively).
Sputum examination revealed a 5.1-fold increase in absolute eosinophil and a 2.9-fold increase in neutrophil numbers after exposure to Molucella laevis during the inhalation challenge $(44.2 \%$ eosinophils and $23.3 \%$ neutrophils of TCC $=21.94 \times 10^{6} / \mathrm{ml}$ ) compared with baseline numbers. Concomitantly, there was a 3.4-fold increase of $\mathrm{PC}_{20}$ to metacholine from baseline to 24 hours after provocation value ( $\mathrm{PC}_{20} 0.43$ and $1.45 \mathrm{mg} / \mathrm{ml}$ respectively).

After four months of avoidance of Molucella laevis and the institution of therapy with inhaled steroids our patient was free of asthmatic symptoms. Concomitantly, a decrease in sputum eosinophil number (3.3\% eosinophils and $66.3 \%$ neutrophils of TCC $=5.09 \times 10^{6} / \mathrm{ml}$ ) and an increase of $\mathrm{PC}_{20}$ to metacholine ( $\left.\mathrm{PC}_{20} 9.7 \mathrm{mg} / \mathrm{ml}\right)$ was found.

\section{DISCUSSION}

Decorative flower allergy and IgE mediated occupational asthma caused by these flowers has been previously reported for freesias, chrysanthemums, Easter lily, and tulips ${ }^{7}$ (floral shop workers), Passiflora alata and Rhamnus purshiana ${ }^{9}$ (pharmacy worker), sunflower ${ }^{10}$ (harvest worker), Dianthus caryophyllus $^{11}$, and Stephanotis floribunda ${ }^{12}$ (greenhouse workers).

In the case presented here, Molucella laevis, a Lamiaceae species, was the only plant present in the greenhouse, and was thus suspected to be the cause of the new-onset asthma in this greenhouse worker with OA. The temporal relation between exposure in the pollination season and asthmatic and other allergic complaints was also suggestive.

We present a complete picture of an allergic asthmatic reaction to a new inhaled allergen, Molucella laevis. We found specific IgE and positive SPT to Molucella laevis (pollen) extract, as well as an EAR and LAR to pollen inhalation with the expected rise in airways eosinophilia and neutrophilia.

Ideally, the inhalation challenge test with Molucella laevis should also have been performed in non-sensitised asthmatic control subjects to exclude the possibility of a non-specific bronchial irritant response. However, in our opinion absence of irritant symptoms in the sentinel subject, a negative SPT result in controls, and the use of an allergen extract preparation method that eliminates low molecular weight chemicals made this possibility unlikely. Furthermore, no cases of OA were found among non-sensitised greenhouse growers in previous studies. $^{2}$

Continued exposure to Molucella laevis may theoretically lead to the development of long lasting poorly reversible bronchial responsiveness and persistent asthma.

We advised our subject to avoid all future exposure to Molucella laevis. Initially, he preferred to continue growing this plant, reducing the intensity of OA by inhaling corticosteroids and $\beta$ adrenergic drugs before exposure to the allergen and by using a protector and improved ventilation in the workplace. But eventually, because of persisting symptoms despite these protective measures, he had to stop growing Molucella laevis.

The cultivation of greenhouse flowers, exposure to specific flower crops, and work inside a greenhouse are risk factors for sensitisation to workplace allergens and bronchial asthma. ${ }^{2}$ It has been estimated that $15 \%$ of flower growers abandon the occupation because of unbearable symptoms. ${ }^{2}$

For decades, many people have used respirators on the job to protect airways. However, reducing inhalation of pollen allergens in the greenhouse by using a respirator should be relied on only as a secondary means of protection. No respirator is fully protective, although an air supplying positive pressure, self contained breathing apparatus offers a high degree of protection. ${ }^{3}$ This high degree of protection comes at a cost. This protector is heavy and its use is limited to less than 30 minutes. The extra weight of the tank, high temperatures, high workload, required maintenance level, and interference with eyeglasses can exact a heavy toll on the wearer's endurance. 


\section{Authors' affiliations}

W M A J Miesen, S van der Heide, A E J Dubois, J G R de Monchy, Department of Allergology, Clinic for Internal Medicine, Groningen

University Hospital, Groningen, Netherlands

H A M Kerstiens, Department of Pulmonology, Clinic for Internal Medicine, Groningen University Hospital

Correspondence to: $\operatorname{Dr}$ W M A J Miesen, University Hospital Groningen, Hanzeplein 1, PO Box 30001, 9700 RB Groningen, Netherlands; w.m.a.j.miesen@int.azg.nl

Accepted 12 November 2002

\section{REFERENCES}

1 Toren K, Brisman J, Olin AC, et al. Asthma on the job: work-related factors in new-onset asthma and in exacerbations of pre-existing asthma. Respir Med 2000:94:529-35.

2 Monso E, Magarolas R, Badorrey, et al. Occupational asthma in greenhouse flower and ornamental plant growers. Am J Respir Crit Care Med 2002; 165:954-60.

3 Martyny J, Glazer CS, Newman LS. Respiratory protection. Current concepts. N Engl J Med 2002;347:824-30.

4 Cockcroft DW, Killian DN, Mellon JJ, et al. Bronchial reactivity to inhaled histamine: a method and clinical survey. Clin Allergy 1977;7:235-43
5 Peebles RS Jr, Hartert TV. In vivo diagnostic procedures: skin testing, nasal provocation, and bronchial provocation. Methods 1997; 13:14-24.

6 Berge van den $M$, Meijer RJ, Kerstjens $H A$, et al. $P_{2}$ adenosine 5 '-monophosphate is more closely associated with airway inflammation in asthma than $\mathrm{PC}_{20}$ metacholine. Am J Respir Crit Care Med 2001;163:1546-50.

7 Piirila P, Kekinen $\mathrm{H}$, Leino $\mathrm{T}$, et al. Occupational asthma caused by decorative flowers: review and case reports. Int Arch Occup Environ Health 1994;66:131-6.

8 Piirila P, Kanerva L, Alanko K, et al. Occupational lgE-mediated asthma, rhinoconjunctivitis, and contact urticaria caused by Easter lily (Lilium longiflorum) and tulip. Allergy 1999:54:273-7.

9 Giavina-Bianchi PF Jr, Castro FF, Machado ML, et al. Occupational respiratory allergic disease induced by Passiflora alata and Rhamnus purshiana. Ann Allergy Asthma Immunol 1997;79:449-54.

10 Bousquet J, Hivert $\mathrm{H}$, Clauzel AM, et al. Occupational allergy to sunflower pollen. J Allergy Clin Immunol 1985;75:70-5.

11 Sanchez-Guerrero IM, Escudero Al, Bartolome B, et al. Occupational allergy caused by carnation (Dianthus caryophyllus). J Allergy Clin Immunol 1999;104:181-5.

12 Zee van der J, Jager de KSN, Kuipers BF, et al. Outbreak of occupational allergic asthma in a Stephanotis floribunda nursery. J Allergy Clin Immunol 1999;103:950-2.

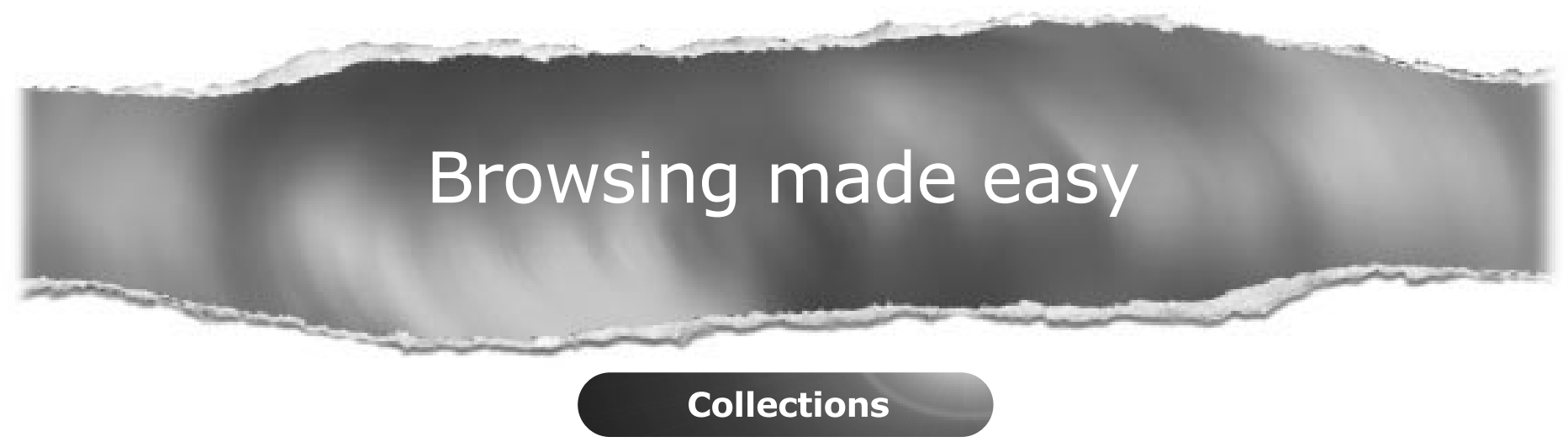

With a single click Collections allows you to find all articles that have been published in your chosen subject. Select from over 200 clinical and non-clinical topic collections and/or cross search other specialist journals, the BMJ and Cochrane Reviews

www.occenvmed.com 